\title{
Abortion clinic websites blocked at Toronto hospital
}

- Cite as: CMAJ 2020 September 8;192:E1049-50. doi: 10.1503/cmaj.1095893

Posted on cmajnews.com on August 20, 2020

t. Joseph's Health Centre in Toronto is no longer blocking staff access to some abortion clinic websites after CMAJ questioned the Catholic hospital about the practice as part of researching this article.

CMAJ spoke to three physicians at St. Joseph's who expressed concern that abortion-related websites were blocked by an internal firewall.

Until mid-August, when the physicians attempted to access abortion clinic websites, they saw a page that read, "Web Page Blocked! You have tried to access a web page which is in violation of your Internet usage policy." The page included the line, "Category: Abortion." The physicians said that morgentaler.ca and bloorwestwomensclinic.com were among the blocked websites.

One emergency physician at St. Joseph's said they were surprised to discover the firewall when attempting to refer a patient for an abortion. "It's 2020; this is pretty unacceptable," said the physician, who spoke anonymously out of fear of career repercussions.

The physician said they would have liked to print information from the website, including a map showing the location of the clinic and information about what to expect in the procedure, "just like I would if I were referring a patient to a sports medicine clinic."

Instead, the physician used their personal phone to access the website and wrote down the phone number and address for the patient.

"If a patient is feeling vulnerable, the more information you can provide them in that moment, the better," the physician said. "Especially for an extremely disadvan-

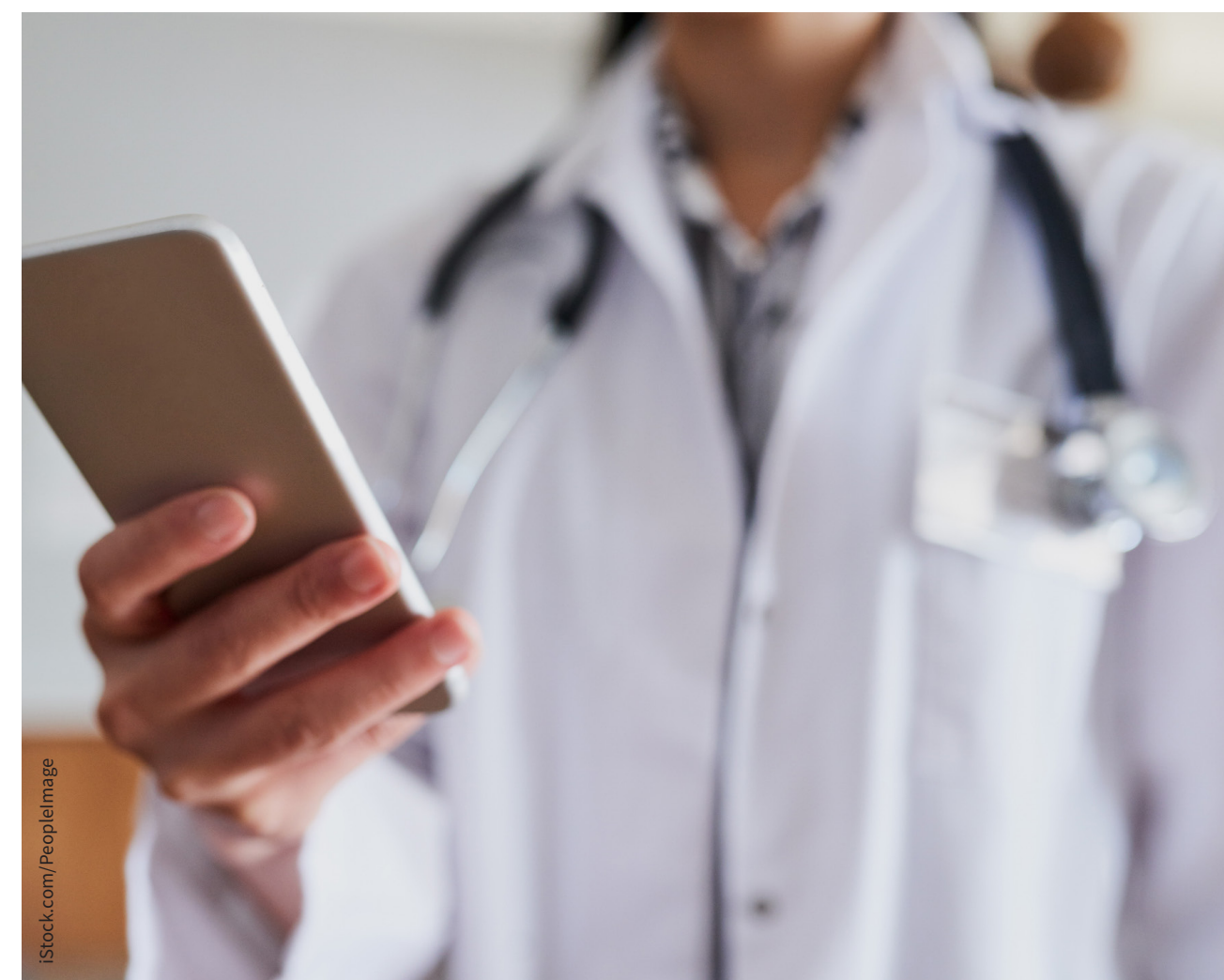

Doctors at St. Joseph's Health Centre are concerned by institutional firewalls blocking abortion information.

taged person, not being able to provide full information could mean they delay accessing the service until it's too late."

Another doctor who spoke anonymously for fear of workplace repercussions noted that their regulatory college mandates them to provide effective referral for abortion. "I feel uncomfortable with [the hospital] restricting access to effective referral," the doctor said. "There is no other issue where l'd be referring a patient and l'd have to scribble a number on the back of a piece of paper. It doesn't look very professional."
CMAJ asked the communications department at Unity Health Toronto why the websites were blocked at St. Joseph's, and why they were not blocked at St. Michael's Hospital, given that the hospitals merged under one board in 2017.

According to Jennifer Stranges, a communications advisor at Unity Health, the firewall at St. Joseph's is set up to cast a wide net and websites related to abortion "often have non-credible, malicious or inappropriate content."

Staff and medical learners can request access to "credible" sites, Stranges said. 
She confirmed that "access to morgentaler. ca and bloorwestwomensclinic.com is no longer restricted" after CMAJ brought those websites to the hospital's attention.

Stranges added that hospitals in the network are still harmonizing technologies since integrating three years ago, "explaining why the sites were blocked at St. Joseph's but not at St. Michael's."

Ontario's Ministry of Health told CMAJ that it "does not play a direct role in the governance or management of hospitals." As such, the hospital board and administrators are responsible for overseeing IT services, including Internet and website access.
According to Joshua McLarnon, a senior communications advisor for the College of Physicians and Surgeons of Ontario, doctors have a responsibility to "proactively maintain an effective referral plan for the services they are unwilling or unable to provide."

Although the College doesn't have authority over hospitals, "it is our expectation that they work with physicians to ensure that physicians meet their regulatory obligations," McLarnon said. In the case of a blocked clinic website, a proactive plan could include printing materials ahead of time and keeping them in an office at the hospital.
Joyce Arthur, executive director of the Abortion Rights Coalition of Canada, said she was surprised to hear that St. Joseph's blocked clinic websites. Such firewalls "violate the conscience of staff at their hospital who want to help their patients," Arthur said. "It makes me wonder if this is a common practice [at other Catholic hospitals]."

CMAJ was unable to confirm whether other Catholic hospitals in Canada block abortion clinic websites or information about other services that run contrary to Catholic doctrine.

Wendy Glauser, Toronto, Ont. 